\section{In Vitro Propagation of Viburnum treleasei Gand., an Azorean Endemic with High Ornamental Interest}

\author{
Mónica Moura ${ }^{1}$ \\ CIBIO, Research Center in Biodiversity and Genetic Resources-Azores, \\ Departamento de Biologia, Universidade dos Açores, Rua Mãe de Deus \\ 58, Apartado 1422, 9501-801 Ponta Delgada, Portugal
}

\section{Maria Irene Candeias}

Estação Agronómica Nacional, Quinta do Marquês, Av. da República, Oeiras, Portugal

\section{Luís Silva}

CIBIO, Research Center in Biodiversity and Genetic Resources-Azores, Departamento de Biologia, Universidade dos Açores, Rua Mãe de Deus 58, Apartado 1422, 9501-801 Ponta Delgada, Portugal

Additional index words. Viburnum, micropropagation, endemic, Azores islands, conservation

Abstract. The purpose of our research was to establish a protocol for the in vitro culture of Viburnum treleasei, a rare and endangered taxon with high ornamental potential endemic to the Azores islands. The surface sterilization of the explants was better achieved with a pretreatment of $0.1 \%$ (w/v) Benomyl for $2 \mathrm{~h}$ followed by $0.2 \%(w / v)$ $\mathrm{HgCl}_{2}$ for 10 min with agitation. Shoot tips were the most efficient explants for shoot development and single-node segments for proliferation. Woody plant medium (WPM) was adequate for all micropropagation stages. For culture establishment and shoot development, a hormone-free medium was adequate, whereas a $1.1 \mu M$ N6-benzyl adenine medium supplement was more efficient for shoot multiplication. Elongation and rooting could be carried out on a $1.3 \mu M$ 1-naphthaleneacetic acid-supplemented medium. Acclimatization of in vitro-produced plantlets was achieved after 1 month with a success rate of $50 \%$. This in vitro propagation procedure will be useful for the conservation of Viburnum treleasei through production of morphologically true-to-type plants, allowing the recovery of depleted natural populations. Chemical names used: N6benzyl adenine (BA); 1-naphthaleneacetic acid (NAA); $\mathbf{H g C l}_{2}$ (mercury bichloride). lignescens (Silva and Debergh, 1997), and Vaccinium cylindraceum (Pereira, 2006).

As a result of the common use of classical vegetative multiplication methods to propagate Viburnum taxa (Cocozza Talia et al., 2004; Dirr and Heuser, 1987; Hartmann et al., 1990), few micropropagation protocols are available. The most efficient procedures for initiation, multiplication, elongation, rooting, and acclimatization of these taxa varied with respect to explant type, medium composition, and other culture conditions (Hildebrandt and Harney, 1985; Ibañez et al., 2003; Nobre et al., 2000; Shoene and Yeager, 2005).

The objective of our study was to develop an efficient micropropagation technique for $V$. treleasei to be used in conservation actions or with a horticultural purpose. To achieve this goal, different explants, surface sterilization methods, and media conditions were tested.

\section{Materials and Methods}

Culture establishment and shoot development. Plant material was collected from São Miguel Island at the locality of Lombadas, where remnants of a medium-altitude natural population of $V$. treleasei still exist. Apical cuttings from the season's growth with vegetative buds $\approx 2 \mathrm{~mm}$ long were the explant source. Six-centimeter long segments were isolated and surface-sterilized using two different methods (A and B). In Method A, surface sterilization started with a pretreatment of $0.1 \%(\mathrm{w} / \mathrm{v})$ Benomyl for $2 \mathrm{~h}$ followed by $0.2 \%(\mathrm{w} / \mathrm{v}) \mathrm{HgCl}_{2}$ with two drops of polysorbate 20 per $100 \mathrm{~mL}$ for 10 min with agitation and three rinses with autoclaved distilled water. Method B was similar to A but at half-strength disinfectant
Only $7 \%$ of the 947 vascular plant taxa given for the Azores Archipelago are considered endemic (Silva et al., 2005). Viburnum treleasei Gand. (Fig. 1A), of the Adoxaceae family (Backlund, 1996), is a hermaphroditic shrub or small tree endemic to the Azores islands. As a result of long-term human pressure over the native vegetation areas, several of these endemic taxa are currently rare or very rare (Schäfer, 2003), and the development of conservation strategies for the endemic Azorean flora is a compelling priority.

Micropropagation has great potential for the protection of endangered endemic taxa (Bramwell, 1990; Osorio-Rosales and MataRosas, 2005) by allowing genotype maintenance and resolution of problems related to self-incompatibility, fertility, low seed production, and low germination. This technique has already been applied to several Azorean endemics such as Hypericum foliosum (Moura, 1998), Azorina vidalii, Angelica

Received for publication 21 Apr. 2009. Accepted for publication 21 July 2009.

${ }^{1}$ To whom reprint requests should be addressed; emailmoura@uac.pt.
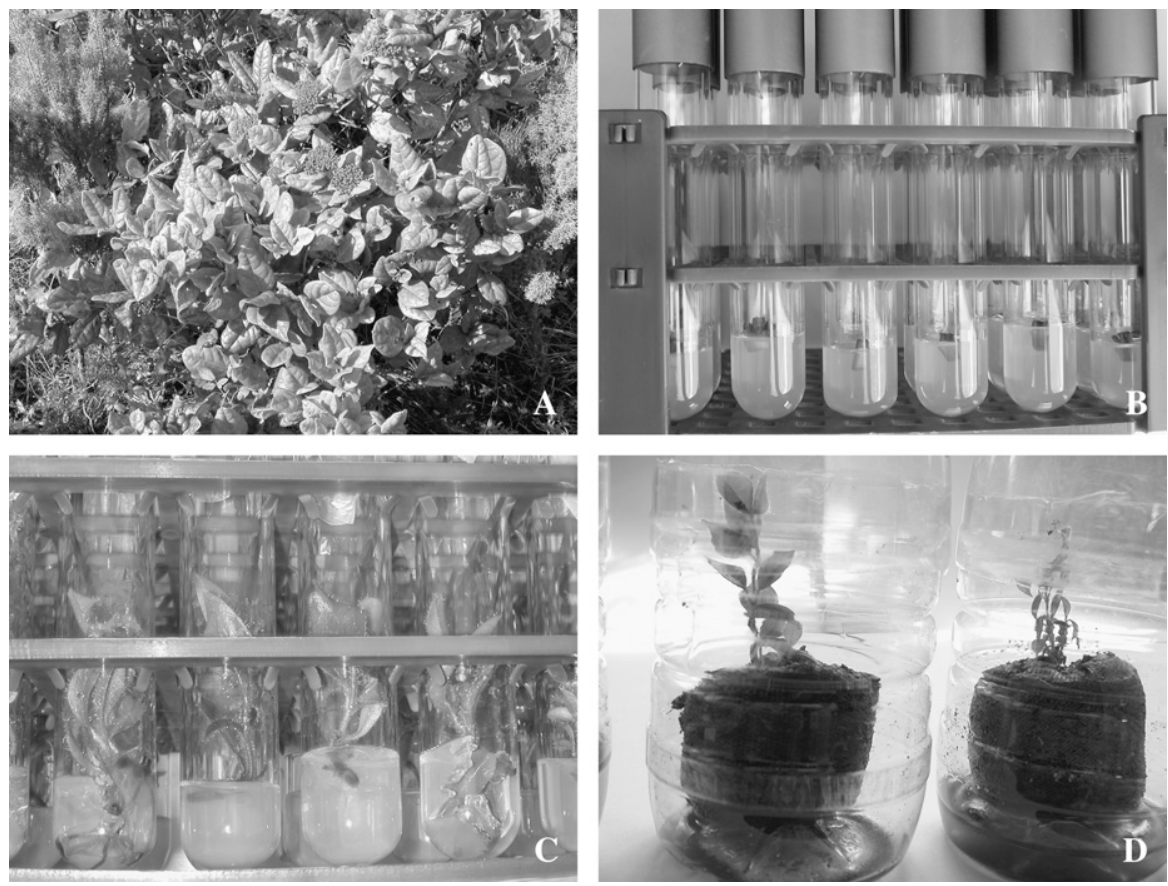

Fig. 1. (A) Specimen of Viburnum treleasei in its natural habitat. (B) Establishment of explants in WP medium. (C) Elongated shoots on the rooting stage. (D) Rooted shoots at the beginning of the acclimatization process. 
concentration and exposure time. For culture establishment, single-node segments, shoot tips, and meristems were used with Method A, whereas single-node segments and shoot tips were used with Method B (Fig. 1B). The apical portion of the cuttings was severed in a $5 \mathrm{~mm}$ segment to obtain the shoot tip, and the subapical portion was cut in $\approx 7 \mathrm{~mm}$ singlenode segments. For the meristems, all bud scales and a pair of leaf primordia in the larger buds were removed to a final size of $\approx 1 \mathrm{~mm}$. MS (Murashige and Skoog, 1962), QL (Quoirin and Lepoivre, 1977), and WP (Lloyd and McCown, 1981) media were tested to determine their influence on shoot development and proliferation. The following MS media variations (Sigma-Aldrich, Inc., 2009) were also tested for basal media study: M0153, M2909, M8900, M8280, and $1 / 2$ MS. MS vitamins at full and double strength and their absence were compared. All media contained MS amino acid formulation, $20 \mathrm{~g} \cdot \mathrm{L}^{-1}$ sucrose, $7 \mathrm{~g} \cdot \mathrm{L}^{-1}$ agar, and the $\mathrm{pH}$ was adjusted to 5.6 before autoclaving for $20 \mathrm{~min}$ at $121^{\circ} \mathrm{C}$. Test tubes of $100 \times 15 \mathrm{~mm}$ with autoclavable caps were used as culture vessels in all tests. Cultures were maintained at $19 \pm 1{ }^{\circ} \mathrm{C}$ with illumination by daylight fluorescent lamps with a photosynthetic photon flux density of $33 \mu \mathrm{mol} \cdot \mathrm{m}^{-2} \cdot \mathrm{s}^{-1}$ and a $16-\mathrm{h}$ photoperiod. Growth regulators' effect on shoot development and proliferation was tested using four levels of 1-naphthaleneacetic acid (NAA) $(0,1.3,2.7$, and 5.4 $\mu \mathrm{M})$ and N6-benzyl adenine (BA) $(0,1.1,4.4$, and $8.9 \mu \mathrm{M}$ ).

Multiplication. To determine the best multiplication conditions, shoot tips and single-node segments obtained from shoots developed after 1 month of culture establishment were subcultured in WP media supplemented with five BA concentrations $(0,1.1$, $2.2,4.4$, and $8.9 \mu \mathrm{M})$.

Shoot elongation and in vitro rooting. To induce shoot elongation and rooting, WP medium was supplemented with three concentrations of NAA $(1.3,2.7$, and $5.4 \mu \mathrm{M})$ and four combinations of NAA $+\mathrm{BA}(0,1.3+$ $1.1,2.7+1.1,5.4+1.1 \mu \mathrm{M})$.

Acclimatization. Plantlets were removed from the culture vessels, washed in distilled water, planted in peat pellets, and kept inside $330 \mathrm{~mL}$ transparent colorless plastic contain-

Table 1. Effect of surface sterilization method (A and B) on Viburnum treleasei explant contamination after 4 weeks of culture.

\begin{tabular}{llc}
\hline \multicolumn{2}{l}{ Treatments } & Contamination (\%) \\
\hline $\mathrm{A}^{\mathrm{z}}$ & Single-node segments & $50.00 \pm 0.00 \mathrm{c}^{\mathrm{x}}$ \\
& Shoot tips & $20.00 \pm 0.00 \mathrm{a}$ \\
& Meristems & $30.95 \pm 2.38 \mathrm{~b}$ \\
$\mathrm{~B}^{\mathrm{y}}$ & Single-node segments & $70.00 \pm 0.00 \mathrm{~d}$ \\
& Shoot tips & $33.33 \pm 3.33 \mathrm{~b}$ \\
\hline
\end{tabular}

${ }^{\mathrm{z}} 0.1 \%(\mathrm{w} / \mathrm{v})$ Benomyl $(2 \mathrm{~h}), 0.2 \%(\mathrm{w} / \mathrm{v}) \mathrm{HgCl}_{2}$ with

2 drops $/ 100 \mathrm{~mL}$ of polysorbate 20 (10 $\mathrm{min})$, followed by three rinses with water.

${ }^{y}$ Same as A but at half-strength disinfectant concentration and exposure time.

${ }^{\mathrm{x}}$ Means ( \pm SE) within a column followed by the same letters are not significantly different (Tukey, $P>0.05)$. ers with adjustable aeration. Hardening of the plantlets to lower humidity levels was conducted through an increase in aeration of the containers. After 2 weeks, the plantlets were removed from the containers and potted in a peat/perlite mix (1:1). Acclimatization occurred under natural illumination and photoperiod and an average temperature of $19{ }^{\circ} \mathrm{C}$.

Data collection and statistical analysis. All experiments were carried out three times with 10 single-explant replications within each treatment. Data were collected after culture periods of 4 weeks, except for contamination and necrosis, which was observed on a weekly basis for 4 weeks. Normal shoot development and proliferation were evaluated using the following parameters: percentage of explants with shoot development, number of shoots per explant, number of nodes per explant, and shoot length $(\mathrm{mm})$. Only shoots longer than $2 \mathrm{~mm}$ were considered suitable for use in the following culture stages. Elongation and rooting of normal shoots was expressed in terms of shoot length increment $(\mathrm{mm})$ and percentage of rooted shoots. During acclimatization, the development of the plantlets was evaluated monthly to determine plant survival rate and morphological conformity. Data normality was determined with the Kolmogorov-Smirnov test. Nonnormal absolute data were log transformed and percentage data were arcsine transformed before analysis. Whenever data structure allowed, an analysis of variance (ANOVA) was used. In the cases in which it was relevant to test for main effects and interactions, a two-way ANOVA was performed. A Tukey (honestly significant difference) test was used as the multiple comparison procedure. For stubborn nonnormal data, the Kruskal-Wallis nonparametric test was applied. Statistical analyses were performed using SPSS 15.0 (SPSS Inc., Chicago, IL) and Microsoft Office Excel 2003 (Microsoft Inc., Redmond, WA).

\section{Results and Discussion}

Culture establishment and shoot development. After a 4-week culture period, shoot tips treated with Method A presented the lowest contamination rate $(\mathrm{F}=128.744$; $P<0.001$; Table 1), being more efficient for culture establishment. This conclusion is also supported by Nobre et al. (2000) working with shoots tips and nodal cuttings of $V$. tinus. Single-node segments were the most susceptible to contamination as would be expected for more mature explants (Debergh, 1988; Leifert et al., 1994). Meristems did not significantly reduce contamination rates and their use did not justify the greater amount of time required for explant preparation and in vitro differentiation. Method B was inappropriate for all types of explants when compared with Method A. A "halo" around the explant below the medium surface, as described by Debergh and Maene (1985), suggested the occurrence of endogenous microbial contaminants (Saikkonen et al., 1998). Explant type and surface sterilization methods did not significantly influence explant necrosis $(6.7 \%$ to $16.6 \% ; \mathrm{F}=0.364 ; P>0.05)$.

The shoot development rate was significantly affected by explant type $(\mathrm{F}=427.358$; $P<0.001)$ and by culture medium $(\mathrm{F}=$ 46.622; $P<0.001)$ with interaction $(\mathrm{F}=$ 8.387; $P<0.001)$ between the two factors. WP and QL medium were among the culture media that promoted the highest shoot development rates and the only media that were adequate for both shoot tips and single-node segments (Fig. 2). Culture medium did not influence the number of shoots and nodes

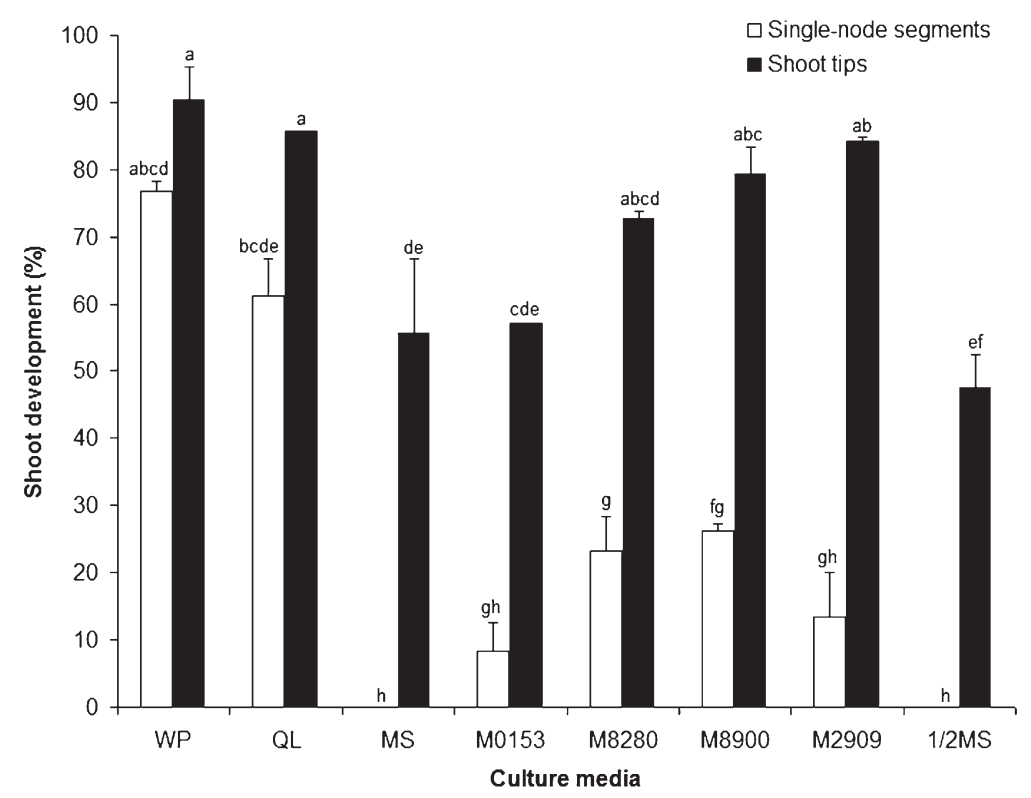

Fig. 2. Effect of nonsupplemented culture media on shoot development from single-node segments and shoot tips of Viburnum treleasei after 4 weeks of culture. Means $( \pm \mathrm{SE})$ followed by the same letters are not significantly different (Tukey, $P>0.05$ ). 
produced per explant using either single-node segments $\left(0-1.8\right.$ shoots and $0-1.9$ nodes; $\chi^{2}=$ $12.501 ; P>0.05$ ) or shoot tips (one shoot and one node; $\chi^{2}=12.604 ; P>0.05$ ). However, after 1 month of culture, only shoots produced from shoot tips on media WP and QL presented suitable development.

Different vitamin concentrations did not significantly influence shoot development (50\% to $91.7 \%$ explants with shoots; $\mathrm{F}=$ $0.834 ; P>0.05)$ and proliferation $(0.5-1.8$ shoots and $0.5-1.9$ nodes per explant; $\mathrm{F}=$ 2.241 and $\mathrm{F}=2.524$, respectively; $P>0.05$ ). These findings are not similar to those reported for $V$. tinus by Nobre et al. (2000), who indicated an advantage of using a doublestrength vitamin concentration.

WP medium proved to be one of the most effective basal mediums tested for culture initiation and was henceforth used in the remaining stages of the in vitro process. The successful use of WP medium in all culture stages was also recorded for $V$. opulus (Ibañez et al., 2003) and in the multiplication, elongation, and rooting stages for $V$. odoratissimum (Shoene and Yeager, 2005).

The shoot development rate was independently $(\mathrm{F}=1.162 ; P>0.05)$ influenced by explant type $(\mathrm{F}=44.540 ; P<0.001)$ and growth regulators concentration $(\mathrm{F}=10.115$; $P<0.001)$. Higher percentages of explants producing shoots were obtained from shoot tips $(78.3 \%)$ than from single-node segments $(42.7 \%)$. For both types of explants, the percentage of shoot development was generally higher in media without growth regulators or with the addition of BA (Table 2).

The number of normal shoots produced per explant was strongly affected by interaction of explant type and growth regulator concentration $(\mathrm{F}=16.880 ; P<0.001)$. Compared with other treatment combinations, single-node segments produced more shoots (Fig. 3) in the absence of growth regulators and on media supplemented with BA and was negatively influenced by the presence of NAA.

Effectiveness of BA-supplemented media was also reported in the initiation of $V$. tinus (Nobre et al., 2000) cultures as well as the absence of growth regulators for $V$. opulus (Ibañez et al., 2003). Contrary to Hildebrandt and Harney's (1985) findings in their study with $V$. opulus 'Nanum', in our work, an auxin supplement was not beneficial for shoot development and proliferation. Results obtained on WP medium without growth regulators indicated this treatment as a good choice to induce initial shoot development and proliferation.

Multiplication. There was a significant $(\mathrm{F}=91.263 ; P<0.001)$ effect of explant type on the number of shoots produced per subcultured explant. Single-node segments produced the highest number of shoots (1.75 shoots from single-node segments and one from shoot tips), but this parameter was unaffected by BA concentration $(\mathrm{F}=0.634$; $P>0.05)$ with a mean of 1.37 shoots per explant or by interaction between the two factors $(\mathrm{F}=0.649 ; P>0.05)$.

Table 2. Effect of NAA and BA on shoot development from single-node segments and shoot tips of Viburnum treleasei after 4 weeks of culture.

\begin{tabular}{lcc}
\hline & \multicolumn{2}{c}{ Shoot development (\%) } \\
\cline { 2 - 3 } $\begin{array}{l}\text { Growth regulator } \\
\text { concn }(\mu \mathrm{M})\end{array}$ & Shoot tips & $\begin{array}{c}\text { Single-node } \\
\text { segments }\end{array}$ \\
\hline 0.0 & $90.48 \pm 4.76 \mathrm{ab}^{\mathrm{z}}$ & $76.67 \pm 1.67 \mathrm{a}$ \\
$1.3 \mathrm{NAA}$ & $72.22 \pm 14.70 \mathrm{ab}$ & $16.67 \pm 16.67 \mathrm{bc}$ \\
$2.7 \mathrm{NAA}$ & $50.00 \pm 0.00 \mathrm{~b}$ & $0.00 \pm 0.00 \mathrm{c}$ \\
$5.4 \mathrm{NAA}$ & $66.67 \pm 16.67 \mathrm{ab}$ & $33.33 \pm 16.67 \mathrm{abc}$ \\
$1.1 \mathrm{BA}$ & $91.07 \pm 4.49 \mathrm{ab}$ & $72.22 \pm 14.70 \mathrm{a}$ \\
$4.4 \mathrm{BA}$ & $77.38 \pm 4.29 \mathrm{ab}$ & $38.89 \pm 5.56 \mathrm{abc}$ \\
$8.9 \mathrm{BA}$ & $100.00 \pm 0.00 \mathrm{a}$ & $61.11 \pm 5.56 \mathrm{ab}$ \\
\hline
\end{tabular}

${ }^{\mathrm{z}}$ Means $( \pm \mathrm{SE})$ within a column followed by the same letters are not significantly different (Tukey, $P>$ $0.05)$.

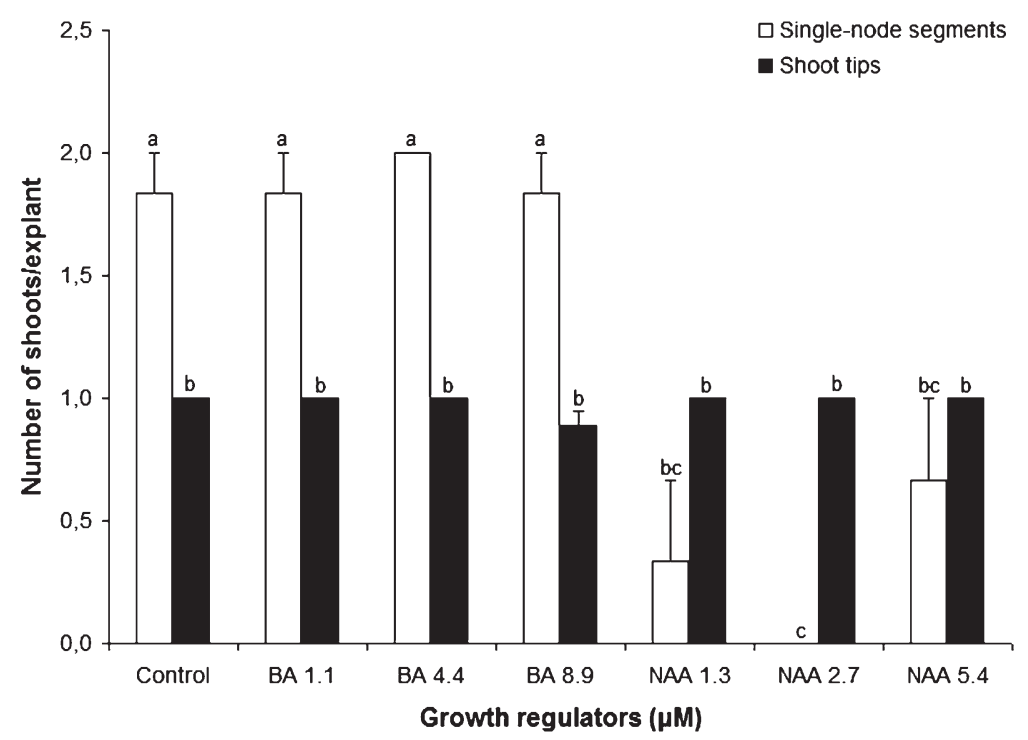

Fig. 3. Effect of growth regulators on the number of shoots per explant from single-node segments and shoot tips of Viburnum treleasei after 4 weeks of culture. Means ( $\pm \mathrm{SE})$ followed by the same letters are not significantly different (Tukey, $P>0.05$ ).

The number of nodes per subcultured explant strongly depended on explant type $(\mathrm{F}=23.785 ; P<0.001)$ and $\mathrm{BA}$ concentration (F $=4.471 ; P=0.01)$, but there was not a significant interaction between these factors $(\mathrm{F}=2.470 ; P>0.05)$. Main effects analysis revealed that single-node segments of $V$. treleasei produced a significantly higher number of nodes per explant (1.83) than shoot tips (1.35) as already reported for $V$. tinus (Nobre et al., 2000). Regarding the number of nodes per explant produced, only $1.1 \mu \mathrm{M}$ BA was appropriate for both types of explants (Table 3 ).

Interaction $(\mathrm{F}=9.798 ; P<0.001)$ of explant type $(\mathrm{F}=222.892 ; P<0.001)$ and BA concentration $(\mathrm{F}=11.489 ; P<0.001)$ had highly significant effects on shoot length. The addition of BA to the medium improved shoot development from both explants, but the increase of its concentration from 1.1 to $4.4 \mu \mathrm{M}$ was advantageous only for those obtained from shoot tips, which produced the longest shoots (Fig. 4). A decrease in shoot length as a result of concentrations higher than 1.1. $\mu \mathrm{M}$ of BA was also reported by Shoene and Yeager (2005) for V. odoratissimum using nodal explants. However,
Table 3. Effect of BA concentration on node proliferation from subcultured single-node segments and shoot tips of Viburnum treleasei after 4 weeks of culture.

\begin{tabular}{lcc}
\hline $\begin{array}{l}\text { BA concn } \\
(\mu \mathrm{M})\end{array}$ & \multicolumn{2}{c}{ Nodes per explant (no.) } \\
\cline { 2 - 3 } & Shoot tips & Single-node segments \\
\hline 0.0 & $1.04 \pm \mathrm{b}^{\mathrm{z}}$ & $1.67 \pm 0.33 \mathrm{a}$ \\
1.1 & $1.98 \pm \mathrm{a}$ & $1.89 \pm 0.22 \mathrm{a}$ \\
2.2 & $1.47 \pm \mathrm{b}$ & $1.89 \pm 0.11 \mathrm{a}$ \\
4.4 & $1.07 \pm \mathrm{b}$ & $1.76 \pm 0.04 \mathrm{a}$ \\
8.9 & $1.35 \pm \mathrm{b}$ & $1.96 \pm 0.11 \mathrm{a}$ \\
\hline
\end{tabular}

${ }^{2}$ Means $( \pm \mathrm{SE})$ within a column followed by the same letters are not significantly different (Tukey, $P>0.05)$.

because shoot tips had a significant lower proliferation rate than single-node segments, the overall results obtained in this study proved single-node segments growing on 1.1 $\mu \mathrm{M}$ BA-supplemented WP medium as the most adequate condition for in vitro multiplication of $V$. treleasei.

Shoot elongation and in vitro rooting. Shoot elongation, calculated as shoot length increment, was not improved by the presence of NAA $(1.3-5.4 \mu \mathrm{M})$ on media containing $1.1 \mu \mathrm{M}$ BA when compared with the growth 


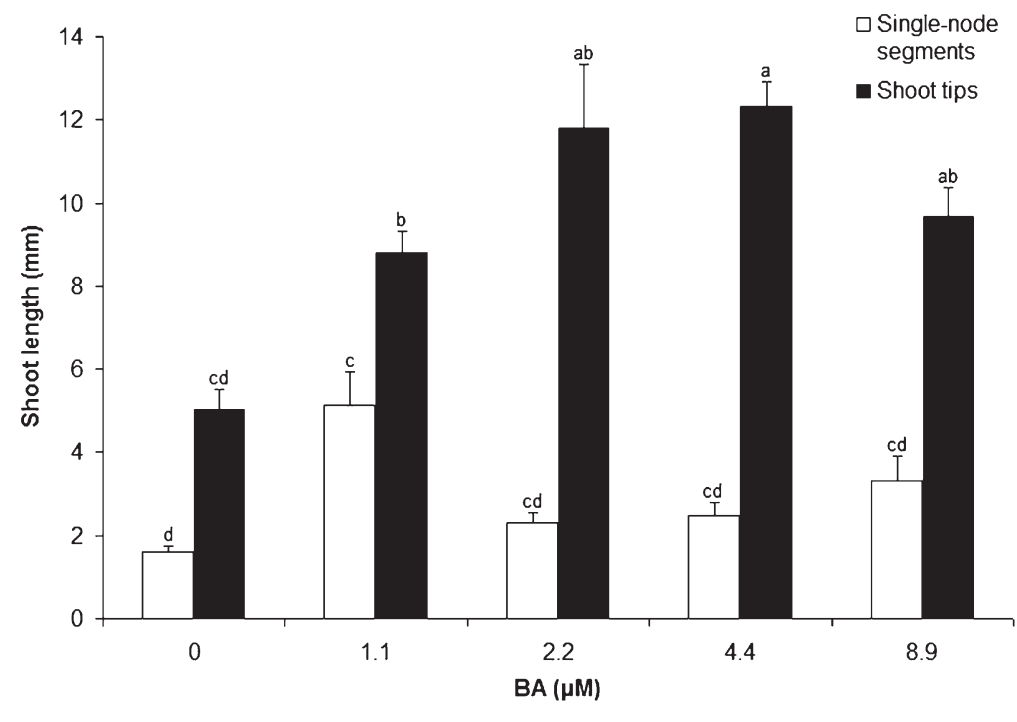

Fig. 4. Effect of BA concentration on shoot length from subcultured single-node segments and shoot tips of Viburnum treleasei after 4 weeks of culture. Means $( \pm \mathrm{SE})$ followed by the same letters are not significantly different (Tukey, $P>0.05$ ).

regulators absence $(3.3-4.7 \mathrm{~mm})$. When alone, the increase of NAA concentration from 1.3 to $5.4 \mu \mathrm{M}$ suggested a negative effect of this auxin on shoot elongation (3.4$1.8 \mathrm{~mm})$. In fact, a borderline significance value was calculated $(\mathrm{F}=2.911 ; P=0.047)$, but the multiple comparisons test did not detect differences between the mean values.

Rooting was possible for $V$. treleasei in the absence of NAA, although in a small percentage $(10 \%)$, and $1.3 \mu \mathrm{M}$ proved to be one of the best NAA concentrations for root initiation (80\%; Fig. $1 \mathrm{C} ; \mathrm{F}=9.298 ; P>0.01)$, as was also reported by Nobre et al. (2000) for $V$. tinus. Because the addition of NAA to a medium with a low level of BA did not improve shoot elongation and restrained rooting, the best option will be to accomplish elongation in step with rooting on a $1.3 \mu \mathrm{M}$ NAA-supplemented medium, in which one of the highest root inductions was achieved without impairing shoot development.

Acclimatization. After 1 month of acclimatization, a survival rate of $50 \%$ was obtained, and all acclimatized plants exhibited normal morphology (Fig. 1D).

In conclusion, $V$. treleasei can be efficiently micropropagated on WP medium, preferably using shoot tips for shoot development and single-node segments for proliferation. Culture establishment and shoot development occur efficiently on a medium without plant growth regulators, whereas shoot multiplication benefits from a $1.1 \mu \mathrm{M}$ BA-supplemented medium. Elongation and rooting should be conducted on a medium with $1.3 \mu \mathrm{M}$ NAA.

\section{Literature Cited}

Backlund, A. 1996. Phylogeny of the dipsacales. Uppsala University, Uppsala, Acta Universitatis Upsaliensis, Comprehensive Summaries of Uppsala Dissertations from the Faculty of Science and Technology 243.

Bramwell, D. 1990. The role of in vitro cultivation in the conservation of endangered species, p. 3-16. In: Bermejo, J.E.H., M. Clemente, and V. Heywood (eds.). Conservation techniques in botanic gardens. Koeltz Scientific Books, Königstein, Germany.

Cocozza Talia, M.A., F. La Viola, and G. Cristiano. 2004. Influence of the sampling time, type of cutting and indole-3-butyric acid (IBA) on cutting rooting of Viburnum tinus L., p. 3340. In: Ciccarese, L., S. Lucci, and A. Mattsson (eds.). Nursery production and stand establishment of broad-leaves to promote sustainable forest management. APAT, Rome, Italy.

Debergh, P.C. 1988. Micropropagation of woody species - State of the art on in vitro aspects. Acta Hort. 227:287-295.

Debergh, P.C. and L. Maene. 1985. Some aspects of stock-plant preparation for tissue culture propagation. Acta Hort. 166:21-24.

Dirr, M.A. and C.W. Heuser. 1987. The reference manual of woody plant propagation: From seeds to tissue culture. Varsity Press, Athens, GA.

Hartmann, H.T., D.E. Kester, and F.T. Davies. 1990. Plant propagation: Principles and practices. 5th Ed. Prentice-Hall, Inc., Englewood Cliffs, NJ.

Hildebrandt, V. and P. Harney. 1985. In vitro propagation of Viburnum opulus 'Nanum'. J. Environ. Hort. 3:41-45.
Ibañez, M.A., C. Martin, and C. Pérez. 2003. Alternative statistical analyses for micropropagation: A practical case of proliferation and rooting phases in Viburnum opulus. In Vitro Cell. Dev.-Pl. 39:429-436.

Leifert, C., C.E. Morris, and W.M. Waites. 1994. Ecology of microbial saprophytes and pathogenes in tissue culture and field-grown plants: Reasons for contamination problems in vitro. Crit. Rev. Plant Sci. 13:139-183.

Lloyd, G. and B.H. McCown. 1981. Commerciallyfeasible micropropagation of Mountain Laurel, Kalmia latifolia, by shoot tip culture. Proc. Int. Plant Prop. Soc. 30:421-427.

Moura, M. 1998. Conservation of Hypericum foliosum Aiton, and endemic Azorean species, by micropropagation. In Vitro Cell. Dev.-Pl. 34:244-248.

Murashige, T. and F. Skoog. 1962. A revised medium for rapid growth and bioassays with tobacco tissue cultures. Physiol. Plant. 15:473497.

Nobre, J., C. Santos, and A. Romano. 2000. Micropropagation of the Mediterranean species Viburnum tinus. Plant Cell Tiss. Org. 60:7578.

Osorio-Rosales, M.L. and M. Mata-Rosas. 2005. Micropropagation of endemic and endangered Mexican species of ponytail palms. HortScience 40:1481-1484.

Pereira, M.J. 2006. Conservation of Vaccinium cylindraceum Smith (Ericaceae) by micropropagation using seedling nodal explants. In Vitro Cell. Dev.-Pl. 42:65-68.

Quoirin, M. and P. Lepoivre. 1977. Improved media for in vitro culture of Prunus sp. Acta Hort. 78:437-442.

Saikkonen, K., S.H. Faeth, M. Helander, and T.J. Sullivan. 1998. Fungal endophytes: A continuum of interactions with host plants. Annu. Rev. Ecol. Syst. 29:319-343.

Schäfer, H. 2003. Chorology and diversity of the Azorean flora. Diss. Bot. 374. J. Cramer, Stuttgart, Germany.

Shoene, G. and T. Yeager. 2005. Micropropagation of sweet viburnum (Viburnum odoratissimum). Plant Cell Tiss. Org. 83:271-277.

Sigma-Aldrich, Inc. 2009. Murashige \& Skoog media variations. Sigma-Aldrich Co. 13 Apr 2009. <http://www.sigmaaldrich.com/life-science/ molecular-biology/plant-biotechnology/tissueculture-protocols/murashige-skoog.html > .

Silva, L., N. Pinto, B. Press, F. Rumsey, M. Carine, S. Henderson, and E. Sjögren. 2005. List of vascular plants (Pteridophyta and Spermatophyta), p. 23-68. In: Borges, P.A.V., R. Cunha, R. Gabriel, A.F. Martins, L. Silva, and V. Vieira (eds.). A list of the terrestrial fauna (Mollusca and Arthropoda) and flora (Bryophyta, Pteridophyta and Spermatophyta) from the Azores. Direcção Regional do Ambiente and Universidade dos Açores, Horta, Angra do Heroísmo and Ponta Delgada.

Silva, M.H. and P. Debergh. 1997. The effect of light quality on the morphogenesis of in vitro cultures of Azorina vidalii (Wats.). Feer. Plant Cell Tiss. Org. 51:187-193. 